\title{
Breaking the connections: reducing and removing environmental health risk in the Canadian nuclear power industry
}

\author{
J. Eyles \& J. Fried \\ School of Geography and Earth Sciences, McMaster University, \\ Hamilton, Canada
}

\begin{abstract}
In this paper, we examine how over the past twenty five years the nuclear industry has used various strategies to diminish or remove any environmental health risks that emanate from its practice and activities. Using both industry and critical website materials, we demonstrate how risk is removed by emphasizing its own safety culture in a complex process, its 'clean energy' credentials, its role in producing national energy options, close co-operation with its regulators, the ignorance of its critics, the suppression of opposing views and a narrowing risk assessment approach to potential environmental and health hazards. We suggest that the same strategies will be used after the recent Japanese nuclear disaster.

Keywords: branding, Canada, elimination of risk, environmental health, narratives, nuclear industry, power generation.
\end{abstract}

\section{Introduction}

Until the March 2011 catastrophe in Japan, the nuclear power industry seemed to have turned the corner from stagnation in the sector to widespread indications of growth. Since its dark days of 'nuclear winter' and the Chernobyl disaster, the industry has become a vital partner in the production of energy in many jurisdictions. Many countries are gearing up to assess the economic and political consequences of new reactors. Environmental and health concerns appeared of little importance in political decision-making as they had seemingly been dealt with by nuclear technological developments and safety standards. In this paper, we examine how the nuclear industry has reached this point. Paying special 
attention to Canada and Ontario, we will comment on the industry's likely response to the 2011 crisis.

Ramana [1], in a review of nuclear power challenges, notes a widespread talk of nuclear revival, strengthened by 33 new reactors being constructed worldwide. Three main problems are identified, with nuclear weapons proliferation only mentioned as a side note: the high cost of nuclear electricity, the risk of a catastrophic accident and dealing with nuclear waste. Other studies point to elevated health impacts found among those living close to nuclear facilities. Yet the industry worldwide has worked diligently to ensure greater safety through technological and cultural changes within the industry and has addressed public concerns by communicating reassuring information with respect to energy production and nuclear waste. Fears of catastrophic events were dealt with by presenting statistically low probabilities of occurrence, often described as being once in a million years. Engineering standards were established to further better these odds, e.g. with the future Kincardine (Ontario) deep-geologic repository for low- and medium-level waste having an estimated safety factor ten times greater OPG [2]. Farsetta [3] notes that in the United States "the campaign to sell nuclear" has had great success. The industry has a set of varying approaches depending on which 'audience' is being addressed. This nuanced approach is likely to be seen in response to the Japanese nuclear problems. In this paper, we chart these approaches for the main industrial players and their associations and regulators as they use technological knowhow, the idea of fail-safe operations, and local economic power to attempt to remove environmental health risks from public discourse.

\section{Responses of the nuclear industry: a theoretical interlude}

Until March 2011, therefore, the nuclear industry had essentially cemented itself as a key element in the continued economic development of virtually all industrial nations. As Sundquist and Elam [4] argue, the nuclear renaissance has been framed in terms of ensuring security of the energy supply and the need to reduce $\mathrm{CO} 2$ emissions.

Hudson [5] perceptively argues that some organizations must overcome core as well as event stigma. Event stigma emerges from specific events that may cast doubt on the legitimacy of an organization. Core stigma arises from the very attributes of the enterprise, i.e. what it is, what it does and who it serves with what. We do not, however, see these as discrete states. We suggest that for the nuclear industry, event stigma was transformed into core stigma as the fear of nuclear winter became linked not to weaponry but to power production, too. How then does the nuclear industry respond to this stigma? How do they legitimize their activities? We will show how the nuclear industry has changed its approach over time and for different audiences by pointing to its social relevance with key audiences, by pointing to the vital nature of its core activity to society in general, by demonstrating the illegitimacy of those who criticize it, by developing an organizational image of social worth and by enhancing its local and national reputation in terms of recognized parameters (such as scientific 
validity and local community relations). Indeed, it has developed strategies and narratives to enhance its legitimacy and remove core stigma.

Hudson [5] suggests several strategies, some of which seem relevant to the nuclear industry. These strategic responses include specialized ones (where the organizations see themselves as specialized, complex entities), open ones (in which activities are broadly communicated with a normalizing narrative which stresses their societal importance), and network ones (in which the activities of the organizations are seen as linked to those of more legitimized bodies regulators, governments - and/or expressed as part of a network of related companies). Some of these strategies have been noted in the narratives of the nuclear sector. The nuclear industry sees itself as a network of experts which can assist in the management of risk (while providing benefit) and permit the development and enhancement of ontological security. Hazards and insecurities can be managed by these expert systems.

In sum, the nuclear industry has adopted an interpretive strategy in which metaphor and communication are dominant in the development and maintenance of legitimacy (see Chaffee [6]). The nuclear industry has thus played down risk narratives, these being largely 'fact sheets' or reactive responses. Its strategy has been to minimize risk and hazard as it communicates its image and brand. As Loseke [7] notes, the power of the narrative of organizations is to tell convincingly the 'right' story to, we would add, the 'right people in the 'right' way. In this paper, then, we illustrate the sophistication of the industry response to the stigma around its core activities by ignoring, trivializing or minimizing the often unspoken risk.

\section{Data sources, methods and analytic approach}

This paper explores the changing portrayal of environmental health risk by key nuclear companies in Ontario (Atomic Energy of Canada Limited (AECL), Bruce Power, Cameco, Ontario Power Generation (OPG)), their industry associations (Canadian Nuclear Association (CNA), World Nuclear Association (WNA)), and their national and international regulators (Canadian Nuclear Safety Commission (CNSC), International Atomic Energy Agency (IAEA)). These organizations form a complex array of production, regulatory and promoting institutions in Ontario.

The main data collection strategy to obtain material for our analysis utilized the websites of these organizations. As others have observed, public discourses are now best observed in technological media with annual reports and incident data seldom being widely circulated in print (Muhlhausler and Peace [8]).

Furthermore, a wide range of search terms was used and analysed. Analysing texts provides insight into how particular organizations present their image, reputation and brand over time and to different audiences as well as the views of their critics. Through quotations, this paper documents divergent images of the nuclear industry in Ontario. 


\section{Findings}

We now turn to the narratives of the Canadian nuclear industry not only in response to its critics but also in how it communicates with governments and publics in general. We assert these responses try to break or minimize the connection between environmental health risk and industry actions or processes. First, there is the statistical removal of risk, often seen in terms of other exposures being far more dangerous to the environment and human health than plant or company activities.

An example here is the WNA-published and frequently cited comparison of deaths (per TWy electricity) due to major accidents among different production forms, with nuclear (8) having a lower number than electricity produced by hydropower (885), coal (342) or natural gas (85) WNA [9]. Interestingly, not included in this report are numbers related to wind or solar produced energy, perhaps due to the lack of major accidents.

In a press statement after the release of filtered water, OPG [10] commented that the (demineralised) water contained trace amounts of tritium, leading to a maximum potential increase of .56 Becquerel per litre but staying well below the Ontario standard for tritium in drinking water (7,000 Becquerel per litre). From a regulatory perspective, this was a very low level event. However, there is no comment that there is some degree of arbitrariness in such regulatory standards, with Ontario's seventy times greater than that of the U.S. CNSC [11].

In an often-cited, twenty year old book, Cohen [12] examined radiation exposure after accidents and noted that releases are usually minor and only very rarely have been as high as 5-10 millirem (mrem). So Cohen asks how dangerous is 1 mrem of radiation and uses a comparison with natural radiation for his answer. On average, people receive a total dose of about 85 mrem per year from natural sources, or 1 mrem every four days. Thus, an additional 1 mrem of radiation, according to Cohen, increases the risk of dying from cancer by about one in four million and results in a (statistical) reduction in life expectancy by two minutes. To further illustrate the risk associated with such additional radiation, Cohen compares it to daily activities and states that statistically it is as risky as crossing streets five times [12]. Arguments like these, however, do not consider all additive effects, risks related to inhalation of radioactive particles or the foregone investments in public resources that have to be used for clean-up after an 'accident'.

Furthermore, it is argued by proponents, that while there may be minimal risks from radiation, these are outweighed by the benefits nuclear technology provides, namely clean energy, nuclear medicine, and social protection. Small doses are seen as harmless WNA [9] and - as the IAEA [13] states - risks are everywhere and cannot be removed.

Another benefit often cited as advantage of using nuclear energy is the provision of a pollution-free (i.e. without environmental health risk) energy option in a world affected by climate change. Thus, the IAEA [14] has argued that the production of nuclear power produces virtually no greenhouse gas emissions. Following a similar argument, Ontario-based Bruce Power [15] 
promotes its proposed new nuclear power plants to the provincial government in Saskatchewan by describing it as promising for developing clean energy and attracting significant private investment, while addressing an urgent environmental issue.

These arguments ignore any counterclaims that nuclear power is not the climate change panacea. In an exhaustive review, Savacool and Cooper [16] argue, for example, that electricity generation itself is only responsible for forty percent of global greenhouse gas emissions; that nuclear plants cannot easily adjust to load variations; and that nuclear power has higher costs than competitors per unit of net carbon dioxide displaced.

Social protection is also utilized as an argument for enhancing nuclear production (see Committee on Foreign Relations [17]), especially with respect to energy security. Wesley [18] makes a strong case for a worldwide concern about such security, while also flagging some potential problems, such as proliferation of nuclear elements across the world. The anticipated fossil energy depletion and the instability of their supply drive many countries to consider nuclear energy as their alternative energy source for the enhancement of their national energy security. 'Social protection' has been taken up by the nuclear industry and broadened to include citizen and environmental protection.

The nuclear industry also argues that environmental health costs may not exist as their critics are politically motivated or, more importantly, carry out poor or junk science, which then raises the concerns of a scientifically challenged public. For example, Cameco responded to a cancer epidemiologist's publicly raised concerns by criticising the "uninformed view of a biased outsider" for making many unsubstantiated claims (Thorne [19]).

It is interesting to note how science critical of nuclear activities is treated by the industry and is often portrayed as junk science (McGarity [20]). Examples of comparison between good and junk science can be found on the trade organisation's website CNA [21]. Another commonly employed way to marginalise critical voices is the immediate and concerted response to any academic studies or reviews reported in the media through letters to the editor and opinion pieces, e.g. Boreham [22, 23]; Moore [24-26].

According to the nuclear industry, it carries out sound science based on engineering principles and quantitative assessments, unlike its critics. Yet the industry is only an accident away from being accused of living in a glasshouse. Critics point to the problems of its 'fail-safe' branding. As Choo [27] points out, structural impediments may lead to failure, but the 'mentality' of fail-safe may lead to epistemic blind spots and risk denial. Still nuclear advocates, as we have seen, remain optimistic that technological innovation can minimize risk further and insist that critics simply incite fear with their commentaries. Thus, the nuclear 'brand' must be continuously protected in all responses.

Critics do not, the industry claims, understand how it operates and should thus accept that there are only limited environmental health risks due to nuclear technology's in-built operational redundancies in its fail-safe technology. The nuclear industry admits that minimal or theoretical risks exist but emphasises that these are completely controlled through expertise and government 
regulation. The nuclear power sector claims to be the most regulated industry in Canada. So, as was noted about a public inquiry into the deep geologic repository in Kincardine, technical uncertainties are presented by advocates as either already or soon to be solved (Durant [28]). During the inquiry, claims were made "that expert groups could be trusted to have made the right judgments; that sufficient evidence was available to move to siting, because the disposal concept itself was a do-able scientific and engineering problem, and because regulatory bodies were providing adequate oversight [28, p.151]."

Bruce Power [29], on their public website, emphasises that they report to many different levels of government and their agencies and list several of these. In 2006, the company announced its restart plan for two mothballed reactors at the Bruce A Generating Station after receiving CNCS's environmental approval that stated that the restart is "not likely to cause significant adverse environmental effects" (Algie [30]). Interestingly, the renewed operating license for Bruce B also permitted a pilot project for the use of enriched uranium fuel in place of natural uranium [30].

Cameco [31] also described its regulatory environment on its website, noting that the CNSC has lead responsibility for regulating activities at both its Ontario facilities, but detailing also other avenues of monitoring and reporting.

IAEA has also given its approval after inspection of nuclear facilities in Canada. So while well run, some question the arms-length nature of the companies from the regulators. CNSC has been criticized for having an industry and technical mind set. Its budget is provided in significant measure by the companies it regulates. IAEA is also dependent on country-based funding as well as operating in the political climate of the U.N. and its drivers.

From the nuclear sector's perspective, benefits can also be maximized and costs and risks minimized at the local level. In some ways, this is where the nuclear sector can respond easiest to a particular audience and where high paying local jobs and investments are provided and can bolster support. Perceived risks are diminished as benefits are invoked - through local investments in public goods (e.g. clinic), greening, local environmental protection, and sharing the profits (e.g. giving to local community organisations). For example, Bruce Power [32] has "provided $\$ 500,000$ to upgrade diagnostic equipment at the Southampton and Owen Sound hospitals and pledged \$400,000 to the Women's House Serving Bruce \& Grey to help build transitional housing for women and children in need in four local communities." An economic impact study shows direct and indirect spending in Port Hope by Cameco's two local facilities totalled almost $\$ 63$ million in 2005 , accounting for $9 \%$ of the total economic activity in the municipality during that year [31].

\section{Discussion and conclusion}

All the above described removals of risk are encapsulated in the 'nuclear brand'. There is positivity in the nuclear communication responses whether pro- or reactive. This can be best seen in its branding. Yet the nuclear sector has a specific problem, namely its core stigma. Horlick-Jones et al. [33] note the extent to 
which a nuclear label is able to generate a sense of stigma for the technology in question, exerting a powerful influence on the lay imagination.

Nuclear agencies use all the described ideas related to climate change, energy supply security and sound technology in their claims and communications about their role. Reference is made to the natural world, clean production spaces, children as a metaphor for the future and innocence, and blue sky for unlimited thinking and openness. To generalise from CNA, the brand is clean, affordable, future-oriented, attentive of families and their ways of life and mindful of its critics. All they require is the truth to be told.

We have shown how nuclear energy in Canada tried to overcome the tipping point of Three Mile Island and Chernobyl. With its appeals to fail-safe technofixes related to energy security and climate change, the sector placed itself close to government and seemed to be the answer for future energy needs. Through its response strategies to criticisms and its proactive communication styles and images, it reshaped its organizational identity. It was a corporate citizen, giving back to local communities in particular for the right to operate. It had shown resilience and seemed to have overcome core stigma as there were no episodes to produce event stigma. It is became a transparent industry run by dedicated professionals acting rationally on the bases of sound science. And then something happened. Soon after a massive earthquake and tsunami on $11^{\text {th }}$ March 2011, six reactors at the Fukushima Daiichi nuclear power plant in Japan reached various critical levels. Now, the accident is being classified by the IAEA [34] at the highest level 7 of the International Nuclear and Radiological Event Scale, and thus the same as Chernobyl. So after twenty five years of actively breaking the connection between the sector and environmental health risks, they appear to be reconnected. It is too early to know the long-term response, but the usual ones are being put forward - safety flaws; given the catastrophic events, denial that such an event could happen in most nuclear jurisdictions; alternative energy production methods are more deadly, foreign oil dependability grows more fraught, the next generation of nuclear technology will be better. Many sound like arguments still played out to address the concerns of the 1970s and 1980s: déjà-vu all over again.

\section{References}

[1] Ramana, M.V., Nuclear Power: Economic, Safety, Health, and Environmental Issues of Near-Term Technologies. Annual Review of Environment and Resources, 34, pp. 127-52, 2009.

[2] OPG, The Deep Geologic Repository. http://www.opg.com/ power/ nuclear/waste/dgr/, 2011.

[3] Farsetta, D., The campaign to sell nuclear. Bulletin of the Atomic Scientists, 64(4), pp. 38-41, 2008.

[4] Sundquist, G. and Elam, M., Public involvement designed to circumvent public concern? The "Participatory Turn' in European nuclear activities. Policy Studies Organization, 1(4), pp. 203-29, 2010. 
[5] Hudson, B.A., Against all odds: a consideration of core-stigmatized organizations. Academy of Management Review, 33(1), pp. 252-666, 2008.

[6] Chaffee, E.E., Three models of strategy. Academy of Management Review, 10(1), pp. 89-98, 1985.

[7] Loseke, D.R., The study of identity as cultural, institutional, organizational, and personal narratives: theoretical and empirical integrations. The Sociological Quarterly, 48, pp. 661-88, 2007.

[8] Muhlhausler, P. \& Peace, A. Environmental discourses. Annual Review of Anthropology, 35, pp. 457-79, 2006.

[9] WNA, Safety of nuclear power reactors. http://www.worldnuclear.org/info/inf06.html, 2011.

[10] OPG, Low impact filtered water release to environment. http://www.opg.com/news/releases/110316lowlevelwaterrelease.pdf, March 16th, 2011.

[11] CNSC, Standards and guidelines for tritium in drinking water. http://nuclearsafety.gc.ca/pubs_catalogue/uploads/info_0766_e.pdf, CNSC Ottawa, 2008.

[12] Cohen, B.L., The nuclear power option. University of Pittsburgh Press: Pittsburgh, 1990.

[13] IAEA, www.iaea.org, 2011.

[14] IAEA, Climate change and nuclear power. http://www.iaea.org/ Publications/Booklets/ClimateChange/climate_change.pdf, 2000.

[15] Bruce Power. Bruce Power launches Saskatchewan 2020 initiative. http://www.brucepower.com/pagecontent.aspx?navuid=1212\&dtuid=83768 , June 18, 2008.

[16] Sovacool, B.K. and Cooper, Chr., Nuclear nonsense: Why nuclear power is no answer to climate change and the world's post-Kyoto energy challenges. William \& Mary environmental law and policy review, 33(1), pp. 1-119, 2008.

[17] Deutch, J. \& Schlesinger, J.R., National security consequences of U.S. oil dependency. Independent Task Force Report No. 58, www.cfr.org/content/publications/attachments/EnergyTFR.pdf.

[18] Wesley, M., Power Plays: Energy and Australia's Security. Canberra: Australian Strategic Policy Institute, 2007.

[19] Thorne, A., Standing with the people of Port Hope. www.cameco.com/fuel_services/common/.../Cameco_-_Caldicott-mll-lk.pdf, 2010.

[20] McGarity, T., 2003. Our science is sound science and their science is junk science: Science-Based Strategies for Avoiding Accountability and Responsibility for Risk-Producing Products and Activities, Kansas Law Review, 52, pp. 897.

[21] CNA, Canadian Studies. http:/www.cna.ca/english/studies_reports/ canadian studies.html, 2011.

[22] Boreham, D., Opinion: Selective data led to one-sided report The StarPhoenix, 10 July, A6, 2009. 
[23] Boreham, D., The Lemstra nuclear health study is flawed, Northumberland Today. 2009.

[24] Moore, P., Selective citation in Lemstra report. Northumberland Today, 7 July, 4, 2009.

[25] Moore, P., Letters to the Editor, The Calgary Herald. 1 April, 2009.

[26] Moore, P. (2009c). Renewables won't solve all our energy needs, The Toronto Star, 9 July, A18, 2009.

[27] Choo, C.W., Organizational disasters: why they happen and how they may be prevented, Management Decision, 46(1), pp. 32-45, 2007.

[28] Durant, D., Responsible action and nuclear waste disposal. Technology in Society, 31, pp.150-57, 2009.

[29] Bruce Power, Safety and environment. Regulatory reporting, http://www.brucepower.com/pagecontent.aspx? navuid=602, 2011.

[30] Algie, J., Bruce A project gets go ahead, Owen Sound Sun Times, July 6 2006.

[31] Cameco, Frequently asked questions. http://www.cameco.com/ fuel_services/faq/, 2011.

[32] Bruce Power, Bruce Power Celebrates Safety Record with $\$ 15000$ donation to children in need. Press Release August 28 2009, http://www.brucepower.com/pagecontent.aspx?navuid=1212\&dtuid=84053

[33] Horlick-Jones, T., Prades, A. \& Espluga, J., Investigating the degree of "stigma" associated with nuclear energy technologies: a cross-cultural examination of the case of fusion power, Public Understanding of Science, http://pus.sagepub.com/content/early/2010/07/20/0963662510371630.

[34] IAEA, Statement to International Conference on Chernobyl: Twenty-Five Years On - Safety for the Future, by IAEA Director General Yukiya Amano, http://www.iaea.org/newscenter/statements/2011/ amsp2011n010.html, 2011. 